\title{
Assessment of Triazine Herbicides in Soil by Microwave-assisted Extraction Followed by Gas Chromatography Coupled to Mass Spectrometry Detection
}

\author{
Darlan Ferreira Silva, Maria Diva Landgraf and Maria Olímpia Oliveira Rezende \\ Chemistry Institute of São Carlos, University of São Paulo, Avenida Trabalhador São Carlense, São Carlos-SP 13566 590, Brasil
}

\begin{abstract}
An alternative and fast method for the analysis of a mixture of nine triazines herbicides in soil is presented. The method is based on MAE (microwave-assisted extraction) of herbicides using ethyl acetate as extractant. The economy in the use of solvents coupled with the decrease in extraction time and lower power consumption make MAE a technique that meets the principles of green chemistry. MAE operational parameters, extraction time, mass of the sample and extraction temperature, were optimized by RSM (response surface methodology). Determination of analytes was completed using gas chromatograph coupled to mass spectrometry detection. The selected triazines could be efficiently extracted by the solvent at $80{ }^{\circ} \mathrm{C}$ for 10 min, with $80 \%$ output of maximum power. When the optimized method was applied to analysis samples, the recoveries of analytes ranged from 81.8 to $106.0 \%$ and relative standard deviations were lower than $8.41 \%$. The method is stable and reasonable, which can be used for the determination of ninetriazine herbicides residues in soil.
\end{abstract}

Key words: Factorial design, response surface methodology, microwave-assisted extraction, herbicides, triazines.

\section{Introduction}

Currently, herbicides and insecticides have been used to increase agricultural productivity and quality. Triazines are important herbicides for the weed control, however, the continuous use of these compounds results in the contamination of water, groundwater, soil and air [1].

Brazil is one of the world leaders in the production of sugar cane, sugar and ethanol fuel, which is considered a renewable fossil fuel. Conventional sugar cane cultivation requires a large amount of pesticides, being that herbicides accounting for approximately $56 \%$ of the total invested in Brazil. Agricultural intensification, especially in tropical regions, has led to increased consumption of pesticides, leading to increased concern about possible environmental

Corresponding author: Darlan Ferreira Silva, Ph. D., research field: analytical chemistry. contamination [2].

Atrazine is one of the most widely applied herbicides in the world. Its global consumption is estimated at 70,000 t per year. Sugar cane crops are treated with atrazine during the planting stage and/or after emergence. Simazine is less frequently used than atrazine, however, it is included in the control of broadleaf and grassy weeds in fruits, nut, corn and sugar cane crops also. Besides, in agricultural application, simazineis are also used for nonselective weed control on industrial sites and railroads [3].

Most relevant analytical methods to determine herbicides and their transformation products in soil involve many steps, such as sample preparation, extraction, clean-up, fractionation and determination. Modern technologies based on instrumental techniques such MAE (microwave-assisted extraction) have been tested to facilitate sample pre-treatment $[4,5]$.

Extraction of analytes plays a significant role in 
analytical chemistry. Among the various extraction methods, MAE is highlighted due to its speed, simplicity, high extraction efficiency and the low consumption of sample and solvent [6]. Currently, MAE has been applied successfully in the analysis of environmental and food samples, as well as in the isolation of active principles in plants. Energy microwaves are used to heat the solvents in contact with the sample and to transfer the analytes from the sample to the solvent [7]. Consequently, many of the MAE applications involve polar solvents and water, including the moisture of the sample itself.

The aim of the present investigation was to develop a simple and rapid MAE method for analysis of triazine herbicides in soil samples. The application of the MAE for the extraction of triazines was evaluated: extraction temperatures, time and mass of the sample were the evaluated factors.

\section{Experimental}

\subsection{Reagents and Materials}

All solvents and reagents were from analytical grade. Amixture of nine triazines (atrazine, prometryn, ametryn, propazine, secbumeton, simazine, terbuthylazine, simetryn and terbutryn) in ethyl acetate at concentration of $100 \mu \mathrm{g} \cdot \mathrm{mL}^{-1}$ from Dr. Ehrenstorfer (Augsburg, Germany) was used to prepare a work solution. Work solution of the triazines $\left(10.0 \mu \mathrm{g} \cdot \mathrm{mL}^{-1}\right)$ was prepared by appropriate dilution with ethyl acetate and stored at $4{ }^{\circ} \mathrm{C}$.

\subsection{Soil Preparation}

The soil used in the experiments was classified as a silt-loam soil and presented $58.7 \%$ clay, $29 \%$ silt and $11 \%$ sand. The soil was collected near the Luiz Augusto de Oliveira Highway, whose coordinates are $48.876634^{\circ}$ longitude $22.276414^{\circ}$ latitude. Initially, the soil was air dried and sieved in a $2 \mathrm{~mm}$ sieve. In order to remove possible contamination by organic contaminants, $100 \mathrm{~g}$ of the soil were treated with 200 $\mathrm{mL}$ of dichloromethane for $24 \mathrm{~h}$. After this step, the soil was spread on a tray and set in oven at $100{ }^{\circ} \mathrm{C}$ for $4 \mathrm{~h}$, according to the methodology described by Xiong et al. (1999) [8].

\subsection{Chromatographic System}

The chromatographic system was a GC/MS, Shimadzu, GC2010 Plus, equipped with split/splitless injector and a mass spectrometric detector, Shimadzu, MS-QP 2010 Plus. The capillary column was aRtx ${ }^{\circledR}$, $30 \mathrm{~m} \times 0.25 \mathrm{~mm}$ i.d. and $1.0 \mu \mathrm{m}$ film thickness (Restek). Helium of high purity $(99.9990 \%)$ from White Martins at a constant flow rate of 1.28 $\mathrm{mL} \cdot \mathrm{min}^{-1}$ was used as carrier gas. The mass spectrometer was operated in full scan mode for determination of the retention time of the compound and in the SIM mode for the determination of the sample. The ion source and interface temperature were set at 275 and $300{ }^{\circ} \mathrm{C}$, respectively; monitored ions were: $169.10,196.10,210,225,186,201,200,215$, 214, 213, 227, 241 and $226 \mathrm{~m} / \mathrm{z}$.

\subsection{Spiked Sample Preparation}

All the experiments were performed in a real soil sample, previously treated according to item 2.2. The samples used in the optimization assays were prepared by adding $500 \mu \mathrm{L}$ of a solution containing a 10.0 $\mu \mathrm{g} \cdot \mathrm{mL}^{-1}$ triazine mixture to provide a final concentration of $0.50 \mu \mathrm{g} \cdot \mathrm{mL}^{-1}$. The triazines were quantified by means of an analytical curve with 8 concentration levels in the range of 0.001-1.000 $\mu \mathrm{g} \cdot \mathrm{mL}^{-1}$ for each reference material.

\subsection{Microwave-Assisted Extraction}

MAE was performed on a Speedwave Four ${ }^{\circledR}$ microwave digestion system (Berghof, Germany) with built-in non-contact temperature and pressure measurement, with 12 vessels, made entirely from TFM ${ }^{\circledR}$, with a $60 \mathrm{~mL}$ capacity and $1,450 \mathrm{~W}$ maximum power. A sample constituted of $0.300-0.500$ $\mathrm{g}$ was transferred into the extraction vessel and then $10 \mathrm{~mL}$ of ethyl acetate was added into it. The vessels 
were shaken gently for $10 \mathrm{~min}$. After, there vessels were placed into the microwave extraction system. The magnetron power output of the microwave unit was set at $80 \%(1,160 \mathrm{~W})$. The ramp time of $8 \mathrm{~min}$ has been previously set, evaluating the time necessary for the system to reach the programmed maximum temperature $\left(130^{\circ} \mathrm{C}\right)$ [9]. Then the system was turned on and temperature, time, ramp time and power were adjusted according to the experimental design. After completion of the extraction, the vessels were cooled at room temperature for about $30 \mathrm{~min}$. Finally, the extract was filtrated and transferred into a $100 \mathrm{~mL}$ flask. The filtrated was dried by rotary evaporator at $45^{\circ} \mathrm{C}$, dissolved using $1 \mathrm{~mL}$ of ethyl acetate.

\subsection{Experimental Design for Response Surface Methodology}

RSM (response surface methodology) was used to determine the optimal conditions for extraction. For statistical calculations and RSM plots the Origin Pro 8 (v.80724-B724) program was used. A $2^{3}$ factorial design was used to investigate the effects of three independent variables (temperature, time and mass of sample). For optimization assays, the extraction temperature ranged from 80 to $130{ }^{\circ} \mathrm{C}$, the irradiation times evaluated were 10 and $30 \mathrm{~min}$, using a maximum power of $1,160 \mathrm{~W}(80 \%)$ and, the mass of sample ranged from 0.300 to $0.500 \mathrm{~g}$. All experiments were performed in randomized order to minimize the effects of uncontrolled factors that may introduce a bias on the responses. The actual (and encoded) levels of the factors (temperature, time and mass of sample) for each experiment are shown in Table 1.

A two-way interaction linear model was adjusted to the experimental data based on Eq. (1):

$$
\begin{aligned}
\hat{y}=\beta_{0}+\beta_{1} x_{1} & +\beta_{2} x_{2}+\beta_{3} x_{3}+\beta_{12} x_{1} x_{2} \\
& +\beta_{13} x_{1} x_{3}+\beta_{23} x_{2} x_{3}
\end{aligned}
$$

where, $\hat{y}$ is the predicted value (area), $\beta$ 's are the model coefficients, and $x_{1}, x_{2}, x_{3}$ the encoded factors: temperature $\left(x_{1}, 80-130{ }^{\circ} \mathrm{C}\right)$, extraction time $\left(x_{2}\right.$, $10-30 \mathrm{~min})$ and mass of sample $\left(x_{3}, 0.300-0.500 \mathrm{~g}\right)$.

\section{Results and Discussion}

\subsection{Optimization of $M A E$}

In order to obtain high efficiency in the microwave extraction, the experimental parameters temperature, time and mass of sample were investigated. The ramp time ( $8 \mathrm{~min}$ ) was previously defined, evaluating the time required for the equipment to reach the maximum temperature used in the method, i.e., $130{ }^{\circ} \mathrm{C}$, using the lowest possible power, as mentioned before [9]. The equipment does not operate with a fixed power value, however, it uses the programmable power range, thus, the power of the equipment has been set at $80 \%$ $(1,160 \mathrm{~W})$, i.e., the equipment uses the range of 0 to $80 \%$ of power to set the programmed temperature. All optimization experiments were performed in triplicate. MAE conditions consider the interaction of the different factors in the extraction and the linear relationship between the response and the variables. Table 2 shows the significance of the extraction process. The bold numbers indicate the significance of

Table 1 Experimental design $2^{3}$ : actual and encoded levels of the factors.

\begin{tabular}{llll}
\hline Experiment & Temperature $\left({ }^{\circ} \mathrm{C}\right)$ & Extraction time $(\mathrm{min})$ & Mass of sample $(\mathrm{g})$ \\
\hline 1 & $80(-1)$ & $10(-1)$ & $0.300(-1)$ \\
2 & $130(+1)$ & $10(-1)$ & $0.300(-1)$ \\
3 & $80(-1)$ & $30(+1)$ & $0.300(-1)$ \\
4 & $130(+1)$ & $30(+1)$ & $0.300(-1)$ \\
5 & $80(-1)$ & $10(-1)$ & $0.500(+1)$ \\
6 & $130(+1)$ & $10(-1)$ & $0.500(+1)$ \\
7 & $80(-1)$ & $30(+1)$ & $0.500(+1)$ \\
8 & $130(+1)$ & $30(+1)$ & $0.500(+1)$ \\
\hline
\end{tabular}



Chromatography Coupled to Mass Spectrometry Detection

Table 2 Significance levels of parameters (effects) identified by ANOVA (analysis of variance).

\begin{tabular}{lrrrrrrr}
\hline & \multicolumn{1}{l}{$\beta_{0}$} & \multicolumn{1}{c}{$\beta_{1}$} & \multicolumn{1}{c}{$\beta_{2}$} & \multicolumn{1}{c}{$\beta_{3}$} & \multicolumn{1}{c}{$\beta_{12}$} & \multicolumn{1}{l}{$\beta_{13}$} & \multicolumn{1}{l}{$\beta_{23}$} \\
\hline Propazine & $954,652.62$ & $\mathbf{- 2 2 4 , 4 9 0 . 7 5}$ & $\mathbf{- 5 6 7 , 8 5 1 . 0 7}$ & $\mathbf{- 9 9 , 1 8 3 . 5 7}$ & $\mathbf{5 0 , 9 1 6 . 7 5}$ & $-174,113.75$ & $-128,457.75$ \\
Atrazine & $714,720.25$ & $\mathbf{- 9 4 , 8 4 7 . 7 5}$ & $\mathbf{- 4 1 3 , 8 7 1 . 5 6}$ & $\mathbf{- 7 9 , 0 3 3 . 5 7}$ & $-1,830.59$ & $-192,768.51$ & $-103,597.89$ \\
Simazine & $898,893.50$ & $\mathbf{- 1 9 1 , 3 8 6 . 2 5}$ & $\mathbf{- 5 3 3 , 7 5 1 . 0 7}$ & $\mathbf{- 1 0 0 , 6 9 9 . 5 6}$ & $\mathbf{4 6 , 3 1 2 . 0 9}$ & $-199,469.53$ & $-106,225.66$ \\
Terbuthylazine & $7,337.06$ & $1,752.37$ & $\mathbf{- 1 , 8 2 5 . 1 2}$ & 601.62 & $\mathbf{4 7 3 . 7 5}$ & -665.25 & $-1,236.25$ \\
Secbumeton & $580,263.87$ & $\mathbf{- 8 8 , 7 7 0 . 5 0}$ & $\mathbf{- 1 7 , 7 9 5 1 . 2 5}$ & $-126,292.59$ & $\mathbf{1 3 4 , 0 7 4 . 7 5}$ & $\mathbf{2 4 2 , 4 6 4 . 7 5}$ & $\mathbf{4 6 , 9 6 1 . 7 5}$ \\
Prometryn & $289,354,19$ & $\mathbf{- 5 4 , 6 7 7 . 6 2}$ & $\mathbf{- 2 1 8 , 4 3 6 . 1 2}$ & $-76,527.37$ & $-84,693.75$ & $\mathbf{3 6 , 6 9 4 . 2 5}$ & $\mathbf{1 7 9 , 8 8 8 . 7 5}$ \\
Ametryn & $345,191.00$ & $\mathbf{- 1 7 0 , 9 9 7 . 7 5}$ & $\mathbf{- 1 1 0 , 3 9 1 . 2 5}$ & $166,937.45$ & $\mathbf{3 8 , 4 5 4 . 2 5}$ & $\mathbf{1 8 8 , 7 0 0 . 2 5}$ & $\mathbf{1 5 , 9 8 8 . 2 5}$ \\
Simetryn & $109,382.02$ & $\mathbf{- 6 3 2 , 0 9 4 . 7 5}$ & $\mathbf{- 3 8 0 , 7 6 9 . 2 5}$ & $605,144.57$ & $\mathbf{2 1 1 , 1 0 9 . 5 0}$ & $\mathbf{5 7 9 , 4 8 0 . 5 8}$ & $\mathbf{1 4 1 , 6 3 0 . 5 1}$ \\
Terbutryn & $664,906.75$ & $\mathbf{- 3 7 6 , 0 4 4 . 7 5}$ & $\mathbf{- 2 1 1 , 3 8 6 . 3 4}$ & $284,778.75$ & $\mathbf{1 1 5 , 8 0 0 . 0 4}$ & $\mathbf{3 3 8 , 6 4 1 . 1 2}$ & $\mathbf{8 6 , 4 3 3 . 5 6}$ \\
\hline$\beta_{0}$ (avis
\end{tabular}

$\beta_{0}$ (average of responses), $\beta_{1}$ (temperature), $\beta_{2}$ (time) and $\beta_{3}$ (mass of sample). Bold numbers indicate significant factors as identified by the analysis of variance at the $95 \%$ confidence level.

Table 3 ANOVA for the experimental results for atrazine.

\begin{tabular}{llllll}
\hline Source & Sum of square & Degree off reedom & Mean of square & $F$-value & $P$-value \\
\hline Model* & $2.04693 \mathrm{E} 11$ & $\mathbf{3}$ & $6.82309 \mathrm{E} 10$ & 0.90046 & 0.46938 \\
$\mathrm{X}_{1}$ & $3.59844 \mathrm{E} 10$ & $\mathbf{1}$ & $3.59844 \mathrm{E} 10$ & 0.46734 & 0.50537 \\
$\mathrm{X}_{2}$ & $6.85158 \mathrm{E} 11$ & $\mathbf{1}$ & $6.85158 \mathrm{E} 11$ & $\mathbf{2 2 . 3 6 9 3}$ & $3.22619 \mathrm{E}-4$ \\
$\mathrm{X}_{3}$ & $2.49852 \mathrm{E} 10$ & $\mathbf{1}$ & $2.49852 \mathrm{E} 10$ & 0.32121 & 0.57986 \\
$\mathrm{X}_{1} \mathrm{X}_{2}$ & $1.12838 \mathrm{E} 08$ & $\mathbf{1}$ & $1.12838 \mathrm{E} 08$ & 0.00345 & 0.95414 \\
$\mathrm{X}_{1} \mathrm{X}_{3}$ & $1.43723 \mathrm{E} 11$ & $\mathbf{1}$ & $1.43723 \mathrm{E} 11$ & $\mathbf{1 . 8 9 6 7 6}$ & 0.19359 \\
$\mathrm{X}_{2} \mathrm{X}_{3}$ & $4.80272 \mathrm{E} 10$ & $\mathbf{1}$ & $4.80272 \mathrm{E} 10$ & 1.61981 & 0.22723 \\
Error & $9.09277 \mathrm{E} 11$ & $\mathbf{1 2}$ & $7.57731 \mathrm{E} 10$ & & \\
Cor. total & $1.11397 \mathrm{E} 12$ & $\mathbf{1 5}$ & & & \\
& $\mathrm{R}^{2}=0.9885$ & $\mathrm{R}_{\text {ajusted }}^{2}=0.9821$ & & & \\
\hline
\end{tabular}

$* \mathrm{X}_{1}=$ temperature, $\mathrm{X}_{2}=$ time and $\mathrm{X}_{3}=$ mass of sample. Bold numbers indicate significant factors as identified by the analysis of variance at the $95 \%$ confidence level.

the factors as identified by analysis of variance at a $95 \%$ confidence level.

For the majority of the evaluated triazines, the extraction temperature $\left(\beta_{1}\right)$ was not significant, except for the terbuthylazine. The extraction time $\left(\beta_{2}\right)$ was not significant for all triazines. The mass of the sample $\left(\beta_{3}\right)$ was significant for four of the nine compounds studied. The interaction of factors $\beta_{12}$ (temperature $\times$ time) was significant for most compounds, except atrazine and prometryn. The interaction of factors $\beta_{13}$ (temperature $\times$ mass of sample) showed significance for five of the nine compounds evaluated. The interaction of factors $\beta_{23}$ (time $\times$ mass of the sample) was significant for five compounds. These data suggest that applying a lower temperature for a short time is the most effective way to extract triazines from soil using MAE. A polynomial model was adjusted to the experimental data (Eq. (2)). The corresponding ANOVA data are shown in Table 3 for the atrazine, as an example. Analysis of variance for the experimental results was done for all triazines (data not shown).

$$
\begin{aligned}
\hat{y}=7147720.25 & -94847.75 x_{1} \\
& -413871.5 x_{2}-79033.5 x_{3} \\
& -915.25 x_{1} x_{2} \\
& -96384.25 x_{1} x_{3} \\
& -51789.5 x_{2} x_{3}
\end{aligned}
$$

High $F$-value (22.3693) associated with low $P$-value $(3.22619 \mathrm{E}-4)(P<0.05)$ demonstrated that the generated model was statistically significant [10]. The P-values confirm the significance of each coefficient, i.e., in the lower $P$-value is the greatest effect.

So, according to Table 3 , the greatest significant effect is in the extraction time $\left(\mathrm{X}_{1}\right)$, followed by the 
interaction between extraction temperature and mass of sample $\left(\mathrm{X}_{1} \mathrm{X}_{3}\right)$. All the assessed triazines followed the same polynomial adjust.

\subsection{Response Surface Plot Analysis}

Response surface plots are useful when estimating the effects of the interaction between two factors on the response, as well as identifying the maximum response values. The surface graphs were plotted using the z-axis (area) against two independent variables, maintaining a third one at a fixed value. Figs. 1, 2 and 3 show the main interactions in the extraction process for the atrazine compound. Similar but not identical plots were obtained for all other evaluated triazines (data not presented).

Fig. 1 shows the interaction between the extraction time and the mass of sample in the extraction yield. With the decrease in extraction time from 30 to 10 min and a major mass of sample $(0.500 \mathrm{~g})$, better was the response (area) obtained. The extraction equilibrium was reached within 10 min of extraction, this is probably due to the difference between the contact surface of the analyte and the solvent being very large, which causes rapid phase transfer of the analytes, as well as a longer extraction time may have caused degradation of the compound (atrazine).

Fig. 2 shows the interaction between temperature and extraction time. With a decrease in temperature from 130 to $80{ }^{\circ} \mathrm{C}$ and a decrease in the extraction time from 30 to $10 \mathrm{~min}$, better responses are achieved. High temperatures can increase diffusion and, consequently, desorption of the analytes from the matrix and thus improve the extraction efficiency. However, the high extraction temperature can result in the decomposition of the analytes and also increase the risk of explosion of the vessels used in the extraction [9]. The effect of temperature together with the extraction time is critical factors in the extraction of the analytes, i.e., they can be related to the maximum extraction of the compounds and at the same time to promote the degradation of others. Fig. 3 shows the interaction between temperature and mass of sample.

With the decrease of temperature from 130 to $80^{\circ} \mathrm{C}$ and the increase of mass of sample from 0.300 to

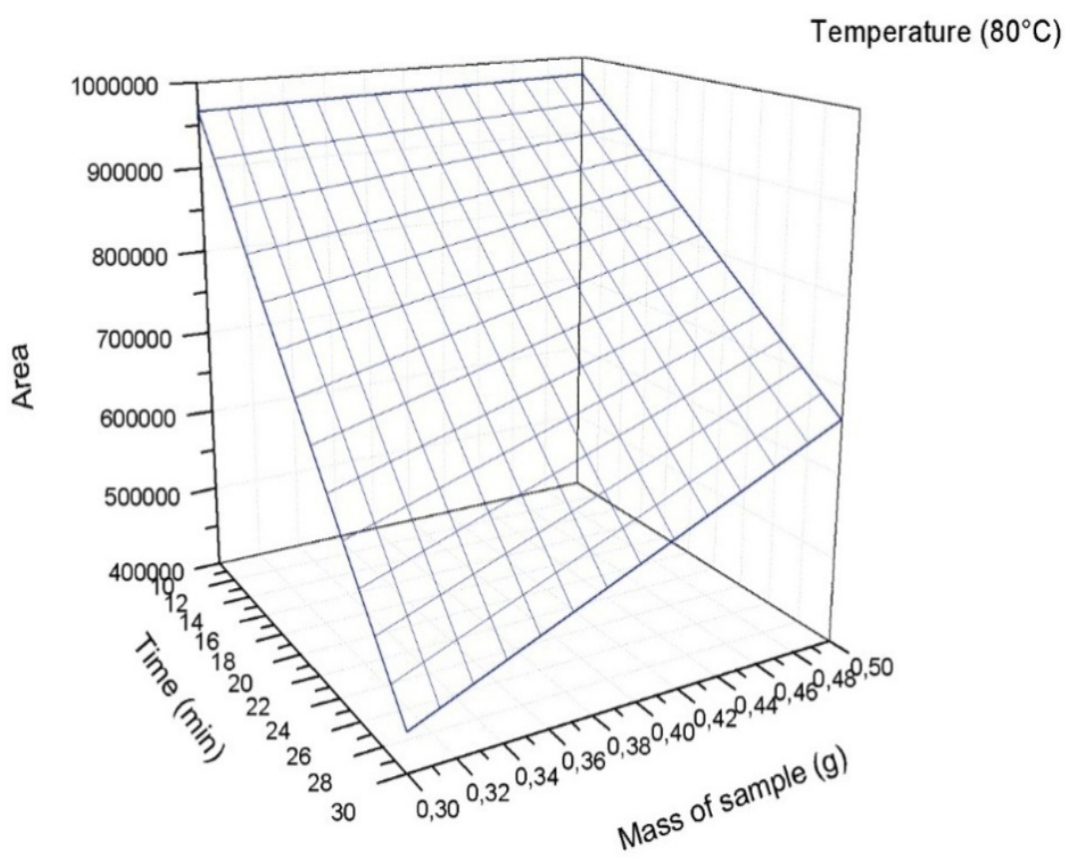

Fig. 1 Response surface plots showing the effect of the variables extraction time and mass of the sample on area of atrazine herbicide. 


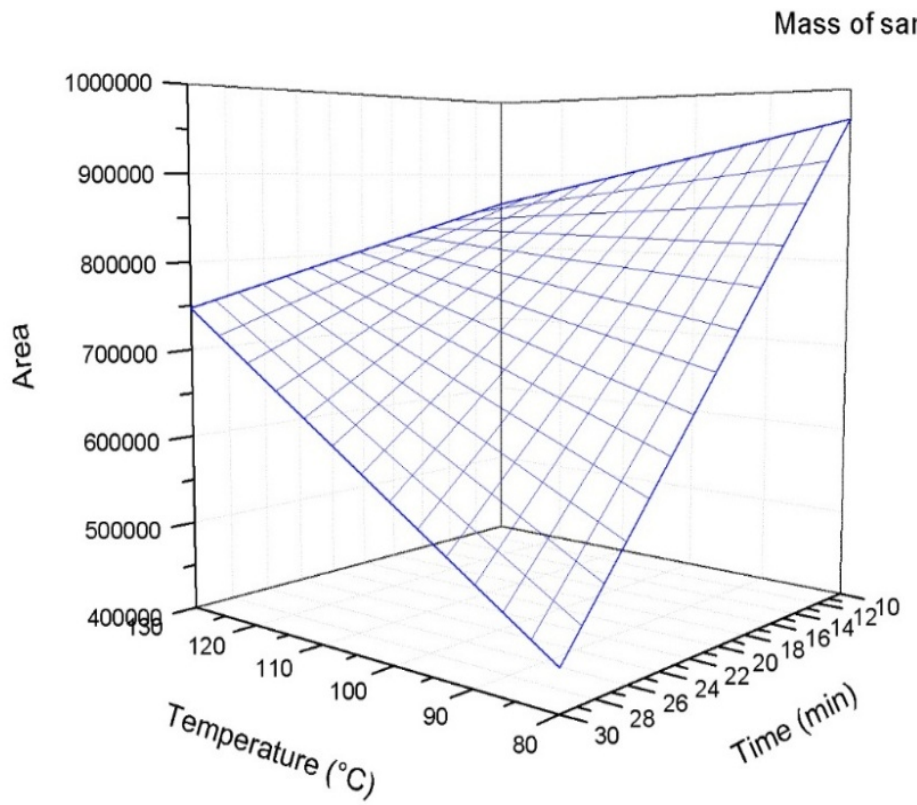

Fig. 2 Response surface plots showing the effect of the variables temperature and extraction time on area of atrazine herbicide.

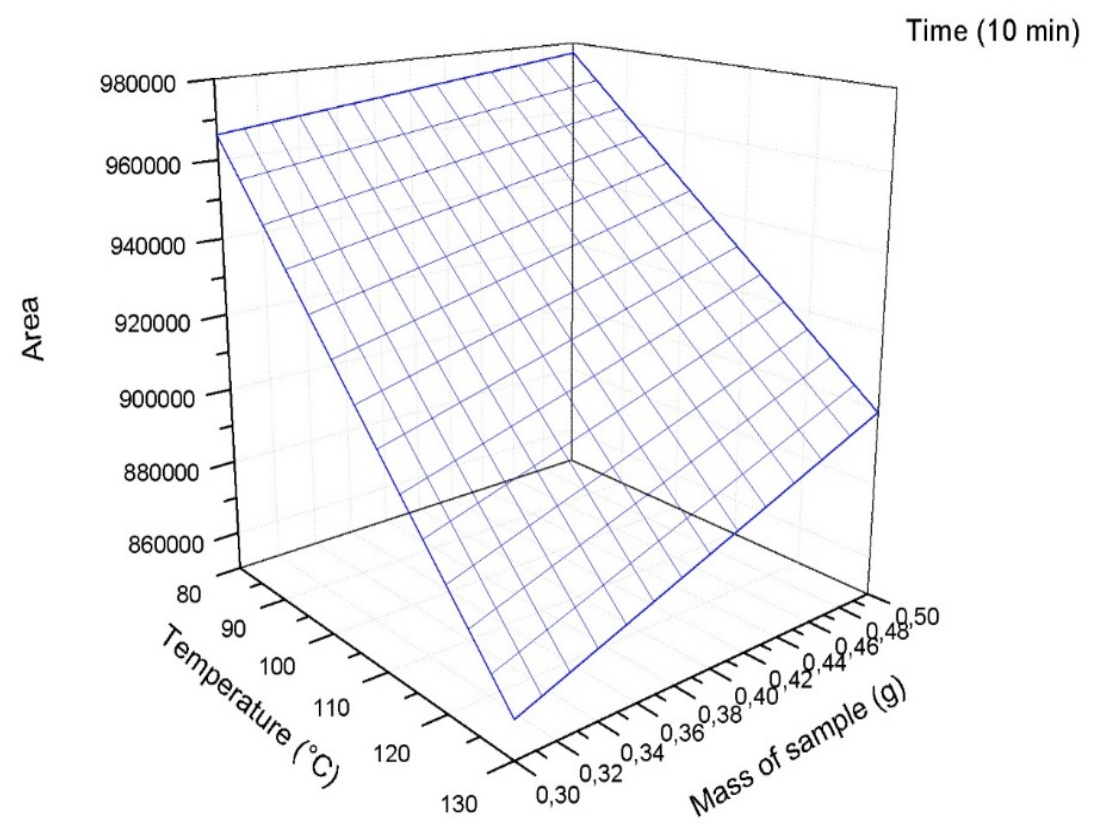

Fig. 3 Response surface plots showing the effect of the variables temperature and mass of the sample on area of atrazine herbicide.

$0.500 \mathrm{~g}$, better responses are achieved. The slight difference in the soil mass used in the extraction generated an increase of $1.14 \%$ in the area of the peak for atrazine, showing that the interaction of the analyte and the amount of sample is significant in the extraction process, as already discussed in Fig. 1.

\subsection{GC-MS Analysis}

As illustration, Fig. 4 shows the GC-MS chromatogram of the mixture of the triazines in scan 


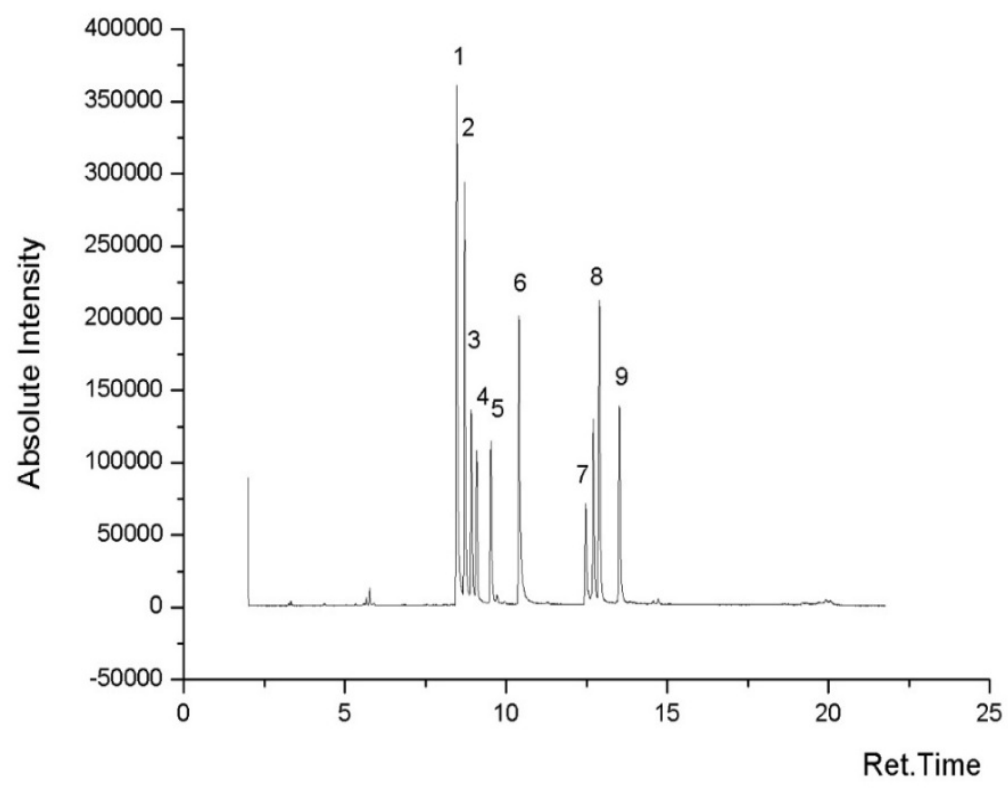

Fig. 4 GC-MS chromatogram of mix of standards. Peaks: (1) propazine, (2) atrazine, (3) simazine, (4) terbuthylazine, (5) secbumeton, (6) prometryn, (7) ametryn, (8) simetryn, (9) terbutryn, at $0.5 \mu \mathrm{g} \cdot \mathrm{mL}^{-1}$. Injection: split (1:10); injector temperature $=$ detector temperature $=280{ }^{\circ} \mathrm{C}$; column temperature $=150{ }^{\circ} \mathrm{C}$; temperature program: $+3.0{ }^{\circ} \mathrm{C} \cdot \mathrm{min}^{-1}$ up to $210{ }^{\circ} \mathrm{C}$. Other chromatographic conditions, see item 2.3 .

Table 4 Average concentrations of detected triazines in spiked soil sample $(n=3)$.

\begin{tabular}{rlllllllll}
\hline $\begin{array}{l}\text { Added } \\
\left(\mu \mathrm{g} \cdot \mathrm{mL}^{-1}\right)\end{array}$ & \multicolumn{2}{l}{ Recovery \pm RSD $(\%)$} & Propazine & Atrazine & Simazine & Terbuthylazine Secbumeton Prometryn & Ametryn & Simetryn & Terbutryn \\
\hline Sample 10 & $81.8 \pm 8.41$ & $82.9 \pm 5.02$ & $91.8 \pm 5.77$ & $84.0 \pm 6.54$ & $91.8 \pm 4.95$ & $95.6 \pm 7.40$ & $95.3 \pm 6.41$ & $100.3 \pm 6.80$ & $91.9 \pm 4.80$ \\
20 & $91.2 \pm 5.29$ & $94.8 \pm 4.11$ & $90.9 \pm 5.33$ & $97.6 \pm 6.70$ & $98.2 \pm 4.67$ & $97.0 \pm 4.20$ & $97.8 \pm 5.35$ & $106.0 \pm 6.73$ & $98.3 \pm 4.23$ \\
50 & $97.2 \pm 5.86$ & $92.6 \pm 4.41$ & $96.3 \pm 6.01$ & $97.8 \pm 6.00$ & $96.6 \pm 5.01$ & $98.2 \pm 6.63$ & $86.6 \pm 4.67$ & $98.4 \pm 6.86$ & $94.8 \pm 4.56$ \\
\hline
\end{tabular}

mode. The analytical curves of all triazines presented a coefficient of determination $\mathrm{R}^{2} \geq 0.99$.

Typical chromatograms of blank and spiked sample were compared. It is seen from the chromatograms of blank that there are no interfering peaks at the retention time of triazines.

\subsubsection{Recovery Assay: Yield of Extraction}

After optimization of the methodology, the yield of extraction was conducted using the parameters defined as the best response in the optimization of microwave-assisted extraction, i.e., the optimal conditions $\left(80^{\circ} \mathrm{C}\right.$ for $10 \mathrm{~min}$, with $0.500 \mathrm{~g}$ of sample) were used to extract, detect and quantify triazines in soil sample.

All triazines were analyzed to evaluate the accuracy and applicability of the present MAE method. The spiked samples were carried out at three fortification levels, 10, 20 and $50 \mu \mathrm{g} \cdot \mathrm{L}^{-1}$ (Table 4). Unspiked blank samples were previously analyzed to determine possible presence of triazines.

Recoveries are between $81.8 \%$ and $106.0 \%$, so the accuracy is acceptable. Recoveries depend upon the matrix, the analytes and the extraction method considered. Then, considering our results in comparison with literature, the present method is suitable for analysis of triazines in soil samples.

Environmental studies generate data to assess pollutant hazards and risks to users and consumers. At the heart of these studies lie analytical data from soil samples, whose accuracy and reliability are of increasingly importance to make technically and administratively correct decisions for a stated purpose. 
So, the optimized method can be considered adequate to analyze the nine selected triazines in soil, consider the advantages of speed, convenience, sensitivity, low cost, and good recoveries that microwave-assisted extraction promotes.

\section{Conclusions}

The current study presents a simple example of experimental design using RSM (response surface methodology) in environmental system, encouraging the elaboration of future studies on the same basis.

This study has demonstrated the feasibility of the use of microwave radiation in the extraction of triazine herbicides in soil sample. Design of experiment provides an efficient working strategy to explore conditions, which ensure the optimum responses of several analytes simultaneously. The RSM is adequate to evaluate how time and temperature of extraction influence in the extraction of the nine selected triazine herbicides from a fortified soil sample.

Additionally, the optimal MAE extraction parameters prove that the extraction of triazines can be done in a single stage, which allows reducing not only the overall analysis time, but also the use of energy.

\section{Acknowledgment}

The authors would like to acknowledge to FAPEMA (Maranhão Foundation for the Protection of Research and Scientific and Technological Development), CNPq (National Council for Scientific and Technological Development), process number 306715/2013-9, FAPESP (São Paulo Research Foundation), process number 2013/13093-7 and NAP 2012-CiTecBio, Provost for Research, University of São Paulo.

\section{References}

[1] Wu, X. L., Meng, L., Wu, Y., Luk, Y. Y., Ma, Y., and Du,
Y. 2015. "Evaluation of Graphene for Dispersive Solid-phase Extraction of Triazines and Neonicotine Pesticides from Environmental Water." Journal of Brazilian Chemistry Society 26: 131-9.

[2] Azevedo, D. A., Silva, T. R., Knoppers, B. A., and Schulz, D. 2010. "Triazines in the Tropical Lagoon System of Mundaú-Manguaba, NE-Brazil.” Journal of Brazilian Chemistry Society 21 (6) 1096-105.

[3] Cheng, J., Liu, M., Zhang, X., Ding, L., Yu, Y., Wang, X., Jin, H., and Zhang, H. 2007. "Determination of Triazine Herbicides in Sheep Liver by Microwave-Assisted Extraction and High Performance Liquid Chromatography." Analytica Chimica Acta 590: 34-9.

[4] Lourencetti, C., Marchi, M. R. R., and Ribeiro, M. L. 2008. "Determination of Sugar Cane Herbicides in Soil and Soil Treated with Sugar Cane Vinasse by Soild-Phase Extraction and HPLC-UV." Talanta 77: 701-9.

[5] Asofiei, L., Calinescu, I., Trifan, A., David, I. G., and Gavrila, A. G. 2016. "Microwave-Assisted Batch Extraction of Polyphenols from Sea Buckthorn Leaves." Chemical Engineering Communications 203 (12): 1547-53.

[6] Li, Y., Fabiano-Tixier, A. S., Vian, M. A., and Chemat, F. 2013. "Solvent-free Microwave Extraction of Bioactive Compounds Provides a Tool for Green Analytical Chemistry." Trends Anal. Chem. 47: 1-11.

[7] Upadhyay, R., Ramalakshmi, K., and Rao, J. M. 2012. "Microwave-assisted Extraction of Chlorogenic Acids from Green Coffee Beans." Food Chemistry 130: 184-8.

[8] Xiong, G., Tang, B., He, X., Zhao, M., Zhang, Z., and Zhang, Z. 1999. "Comparison of Microwave-assisted Extraction of Triazines from Soils Water and Organic Solvents as the Extractants." Talanta 48: 333-9.

[9] Silva, D. F., Landgraf, M. D., and Rezende, M. O. O. 2016. "Optimization of a Microwave-assisted extraction method for the Analysis of the Persistent Organic Pollutant p,p'-DDT in Domestic Sewage Sludge." American Open Chemistry Journal 2 (1): 14-26.

[10] Karabegovic, I. T., Stojicevic, S. S., Velickovic, D. T., Nikolic, N. C., and Lazic, M. L. 2013. "Optimization of Microwave-Assisted Extraction and Characterization of Phenolic Compounds in Cherry Laurel (Prunuslaurocerasus) Leaves." Separation and Purification Technology 120: 429-36. 